\title{
Thermal effects on one-way cyclic behaviour of clay-structure interface
}

\author{
Soheib Maghsoodi ${ }^{1,2 *}$, Olivier Cuisinier ${ }^{1}$, and Farimah Masrouri ${ }^{1}$ \\ ${ }^{1}$ Université de Lorraine, LEMTA (UMR-7563), CNRS, Nancy, France \\ ${ }^{2}$ Ecole supérieur d'ingénieurs des travaux de la constructions de Metz, Metz, France
}

\begin{abstract}
In energy geostructures, which exploit the heat in soil using earth contact elements, the interface is subjected to cyclic thermo-mechanical loads. Monotonic and cyclic constant-volume equivalent-undrained (CVEU) direct shear tests were performed on clay-clay and clay-structure interface at different temperatures (22 and $60{ }^{\circ} \mathrm{C}$ ). Different cyclic and average stress ratios (CSR and ASR) were applied to the kaolin claystructure interface under $300 \mathrm{kPa}$ of normal stress. The results showed that, the number of cycles to failure for the clay-structure interface test was lower than that for the clay-clay case in the same range of cyclic and average shear stress ratios. In cyclic clay-structure tests, decreasing the cyclic stress ratio, increased the number of cycles to failure; however, decreasing the average shear stress ratio decreased the number of cycles to failure. Increasing the temperature, decreased the rate of strain accumulation and the number of cycles to failure increased by 2-3 times. The rate of degradation (degradation parameter, $t$ ) decreased by $16 \%$ with heating from 22 to $60^{\circ} \mathrm{C}$ for the different cyclic stress ratios tested.
\end{abstract}

\section{Introduction}

Incorporation of heat exchangers in conventional geostructures like piles can extract the heat from the soil for heating purposes and inject it to the soil for cooling purposes. The heat exchanger absorber pipes are attached to the reinforcement cage of geostructures [1]. In recent years, research has been conducted at full and laboratory scale to investigate the effect of temperature on the geotechnical behavior of these energy geostructures as well as on the surrounding soil [2-5]. These energy geostructures can be subjected to cyclic mechanical loads and thermal variations throughout their lifetime. The soilstructure interface plays a key role in the transmission of the loads to the ground. It is known that cyclic loads evolve the shear resistance of the soil-structure interface and thus the shaft capacity of the structure. Several studies have been performed on the cyclic behavior of sandstructure interface [6,7], while less is known about the behavior of clay-structure interface [8-10]. In this context, the objective of this study is to investigate the effect of temperature on the cyclic behavior of clay-structure interface. In the following, the current knowledge of the influencing parameters on the cyclic behavior of soil and soil-structure interface is discussed.

The shear stress-strain curve of a soil under cyclic loading can be decomposed into average $\left(\tau_{a}\right)$ and cyclic shear stress $\left(\tau_{c y}\right)$ components, while the deformation can be seen as the combination of permanent shear strain $\left(\varepsilon_{p}\right)$ and cyclic shear strain $\left(\varepsilon_{c y}\right)$ (Fig. 1a). Several parameters, such as the average shear stress, cyclic shear stress, loading frequency ( f ), strain rate $(\dot{\varepsilon})$, number of cycles
$(\mathrm{N})$, normal stress $\left(\sigma_{n}\right)$, temperature $(\mathrm{T})$ and initial state of the soil (normally consolidated or overconsolidated) are mentioned as influencing factors on cyclic response of soils [11-13]. Several studies showed that the number of cycles to failure, $\mathrm{N}_{\mathrm{f}}$, decreases with increasing cyclic shear stress $\left(\tau_{c y}\right)$. Cyclic stress or strain induced deformation accumulation and excess pore pressure lead to soil degradation and can induce failure. [14] introduced the degradation index $(\delta)$ and the degradation parameter $(t)$, that for the stress-controlled tests can be determined as follows:

$$
\delta=\frac{G S N}{G S 1}=\frac{\varepsilon_{c y 1}}{\varepsilon_{c y N}}
$$

where $\mathrm{GS}_{1}$ and $\mathrm{GS}_{\mathrm{N}}$ are the secant moduli at cycles 1 and $\mathrm{N}, \tau_{c}$ is the shear stress value, $\varepsilon_{c y 1}$ and $\varepsilon_{c y N}$ are the cyclic shear strains at cycles 1 and $\mathrm{N}$, respectively. Soil with a high value will have a low degree of degradation [11]. [15] performed temperature-controlled cyclic triaxial tests on kaolin samples. The samples were consolidated under $600 \mathrm{kPa}$ and heated up to $90{ }^{\circ} \mathrm{C}$ in drained conditions and were cyclically sheared under undrained conditions. They found that the initial cycle imposed at either ambient or high temperature produced almost the same axial strain and pore pressure. However later shear cycles of the heated sample induced smaller strain and smaller porewater pressure per cycle. The number of cycles to failure increased for heated samples due to the densification of clay under drained heating and also the pore pressure of heated samples was slightly less than unheated ones. Regarding the impact of temperature on the soil-structure interface, some experimental studies have been performed $[9,16,17]$ on direct shear device and concerning the in-situ

\footnotetext{
* Corresponding author: soheib.maghsoodi@univ-lorraine.fr
} 
behavior; [18] have developed a thermal borehole shear device to study effect of temperature on the in situ shear behavior of soil-concrete interfaces, but to the knowledge of the authors very few studies have been carried out on the thermal effects on the cyclic behavior of clay-structure interface. [9] performed cyclic constant normal stiffness (CNS) two-way strain controlled tests at different temperatures on illite clay. They revealed that testing clay-concrete samples under CNS conditions at higher temperatures, reduces the volumetric contraction during cyclic shearing and the material becomes denser therefore, more cycles are required to degrade the interface strength. With this background there is no literature on the one-way cyclic behavior of clay-structure interface under isothermal or non-isothermal conditions. Therefore, it seems appropriate to investigate that behavior and the effect of temperature on it which provides insight into the strain accumulation, excess pore water pressure and cyclic degradation of the claystructure interface with respect to temperature variations. To do so, two important components of shear cycles $\left(\tau_{a}\right.$ $/ S_{u}^{D S}$ and $\tau_{c y} / S_{u}^{D S}$ ) were varied at different temperatures. The average shear stress represents the allowable shear stress that is mobilized in the structures once the serviceability starts. The cyclic shear stress represents the mechanical solicitations that are imposed to the structure during its lifetime once the average shear stress is reached. Therefore, variations of these parameters can reflect the shear loads applied to the structure. The following aspects that influence the cyclic behavior of clay-structure interface are addressed:

- The effect of average and cyclic shear stress variations $\left(\tau_{a} / S_{u}^{D S}\right.$ and $\left.\tau_{c y} / S_{u}^{D S}\right)$ on clay-structure interface cyclic behavior at different temperatures.

- The effect of temperature on the strain accumulation, equivalent pore water pressure, cyclic loop shape and degradation behavior of the clay-structure interface.

\section{Shear Device, Sample Preparation and Experimental Program}

\subsection{Material properties}

The kaolin clay was used in this study. To perform claystructure interface direct shear tests, a stainless steel plate $(80 \times 60 \times 10 \mathrm{~mm})$ with the desired roughness was designed and used as the structure to avoid the surface abrasion due to test repetition. The roughness of the steel plate was measured with a laser profilometer. The measured average roughness Ra for the profiles was 20 $\mu \mathrm{m}$, therefore, the plate was considered as a rough surface for clay-structure interface $[19,20,24]$.

\subsection{Temperature-controlled direct shear device}

Fig. 1 shows the configuration of the temperaturecontrolled direct shear device. The shear box $(60 \times 60 \mathrm{x}$ $35 \mathrm{~mm}$ ) was placed inside a container filled with water to reach saturated conditions (Fig. 2). The circulating fluid at the bottom of the shear box container was connected to a thermal regulation system. In such a setup, the temperature of the fully saturated shear box container can be controlled by three thermocouples, one in the lower half of the shear box, another on the upper half of the shear box and the last one in the container. The device can be programmed either in stress or deformation controlled tests [17].

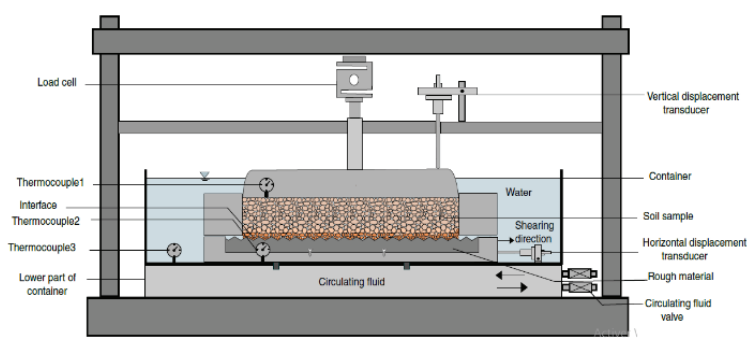

Fig. 1. Temperature controlled direct shear device.

To perform clay-structure shear tests, a slurry of kaolin clay with a water content of $63 \%$, which was slightly higher than its liquid limit $(L L=57)$ was prepared and left for 24 hours for homogenization. Subsequently, the clay was poured into the shear box and special attention was paid to avoid trapping any air. Then, the shear box was placed inside the fully saturated shear box container. Afterwards, the normal stress was applied incrementally during the consolidation phase, each load increment lasted 2 hours and the last step $(300 \mathrm{kPa})$ was left 8 hours to ensure full consolidation. The consolidation phase took 24 hours. Based on the consolidation tests performed on this kaolin clay, the final void ratio after consolidation for $\sigma_{n 0}=300 \mathrm{kPa}$ was e $=0.85$. For tests at $60{ }^{\circ} \mathrm{C}$, a heating rate of $5{ }^{\circ} \mathrm{C} / \mathrm{hr}$ was applied and left for 4 hours to ensure the fully thermal consolidation. This slow rate avoids pore water pressure increase during the heating phase and was verified by $[9,19]$.

\subsection{Experimental program}

To apply equivalent-undrained conditions in the claystructure interface tests, the constant volume equivalentundrained (CVEU) concept was used in this study. In the studies using this concept, as conducted by [21-23], during shearing, in drained conditions while the pore pressure was zero, the change in the vertical stress to keep the volume of the sample constant was equivalent to the pore pressure generated in a truly undrained triaxial test. Several studies have confirmed this approach, using direct shear device [23].

The monotonic program consisted of clay-clay and clay-structure interface tests to determine the essential parameters for cyclic experimental program such as $S_{u}^{D S}$ (undrained shear strength in direct shear). Additionally, the monotonic program can be considered as a reference, to better understand the cyclic behavior of clay-clay and clay-structure interface. The objective of this study is to vary two components of the cyclic shear stress $\left(\tau_{a}\right.$ and $\left.\tau_{c y}\right)$ in a way that reproduces probable cases of interfaces 
in energy geostructures under cyclic loading. Therefore, in order to cover a wide range of stress ratios and apply diverse cyclic paths that can be subjected to the structure, different ranges of cyclic and stress ratios that are mentioned in literature were chosen $[11,13]$. The experimental program consisted of monotonic and cyclic CVEU clay-structure interface direct shear tests at different temperatures which is presented in Fig. 2.

For cyclic tests at different temperatures, the shear stress was increased to the average value ( $\tau_{a}$, path 1-2 in Fig. 2$)$ and then the shear cycles fluctuated in a regular manner between $\tau_{a}+\tau_{c y}$ and $\tau_{a}-\tau_{c y}$ with a frequency of 0.005 Hz. The cycles were continued until a relative lateral displacement of $10 \%$ was reached. Failure was defined when the relative lateral displacement reached $10 \%$. This relative lateral displacement in this was defined as the shear displacement divided by the length of the sample. The volume of the sample was kept constant throughout the tests. The tests consisted of a constant average shear stress ratio $\tau_{a} / S_{u}^{D S}$ (ASR) while varying the cyclic shear stress ratio $\tau_{c y} / S_{u}^{D S}$ (CSR). The objective this type of test was to investigate the effect of cyclic shear stress on the cyclic behavior of clay-structure interface. The cyclic stress ratio $\tau_{c y} / S_{u}^{D S}$ between 0.35 and 0.57 was chosen.

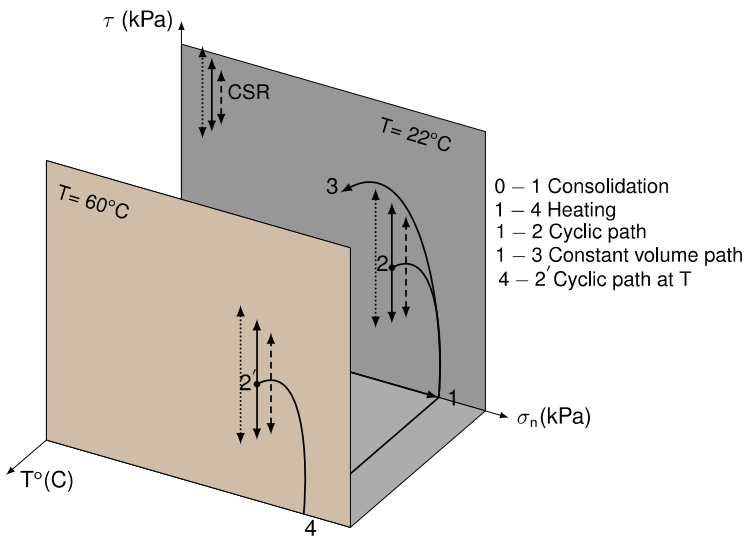

Fig. 2. Cyclic thermo-mechanical path.

\section{Experimental results}

After the consolidation phase, a heating phase with a rate of $5^{\circ} \mathrm{C} / \mathrm{hr}$, was applied to the clay-structure interface. The thermal consolidation curve of the clay-structure interface is shown in Fig. 3. Heating from 22 to $60^{\circ} \mathrm{C}$ caused 0.15 $\mathrm{mm}$ of settlement. After reaching the desired temperature $\left(60^{\circ} \mathrm{C}\right)$, the slope of the thermal consolidation decreased. The thermal vertical strain with heating from 22 to $60{ }^{\circ} \mathrm{C}$ was $0.88 \%$. The comparison of the results obtained during the monotonic tests of the clay-clay and claystructure constant-volume equivalent-undrained (CVEU) shear tests highlighted some significant differences (Fig. 4). The peak shear stress for the clay-structure tests are around $1-1.5 \%$ of relative lateral displacement while for the clay-clay tests the peak occurs in larger relative lateral displacements $(2-3 \%)$.

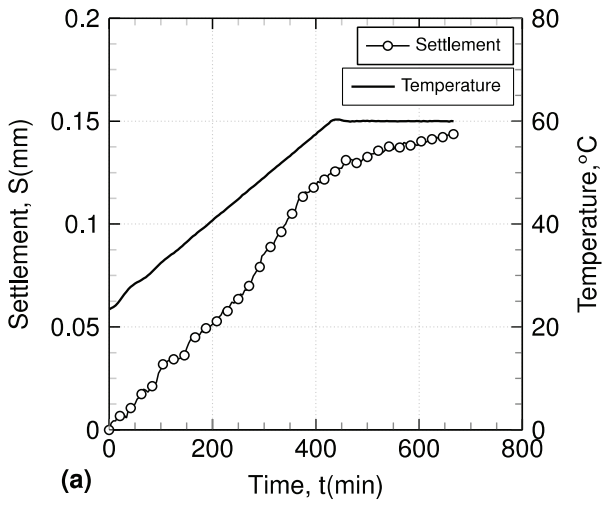

Fig. 3. Thermal vertical settlement upon heating.

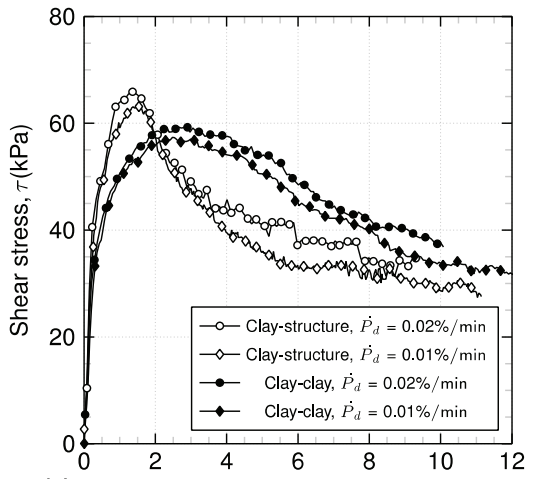

(a) Relative lateral displacement, $P_{d}(\%)$

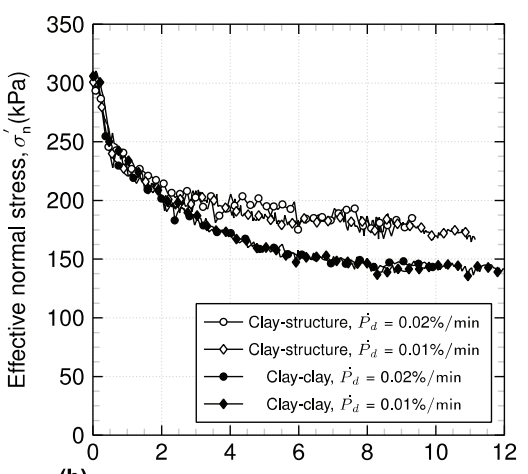

(b) Relative lateral displacement, $P_{d}(\%)$

Fig. 4. Monotonic CVEU clay-clay and clay-structure interface test.

Afterwards the strain softening for clay-structure tests occurred at smaller relative lateral displacements $(2 \%)$ compared to the clay-clay tests, which started from $4 \%$ and continued until the end of the test. These observations confirmed that the shear occurred in the interface zone. Fig. $4 \mathrm{~b}$ shows the variation in the effective normal stress with relative lateral displacement. Due to the normally consolidated state of the soil and to keep the volume of the sample constant, the effective normal stress decreased with shearing for both the clay-clay and the clay-structure tests. The monotonic results permitted to obtain the maximum allowable shear stress. The maximum shear stress was used to propose the cyclic experimental program. 
For the effect of cyclic stress ratio (CSR) variations at different temperatures, a series of tests with an average shear stress of $\tau_{a} / S_{u}^{D S}=0.41$ (Fig. 5) was performed. For $\tau_{a} / S_{u}^{D S}=0.41$, the cyclic stress ratio (CSR) varied from 0.35 to 0.57 at different temperatures (22 and $60{ }^{\circ} \mathrm{C}$ ). Reduction of CSR from 0.57 to 0.35 increased the number of cycles to failure from 39 to 4200 cycles (Fig. 5a).
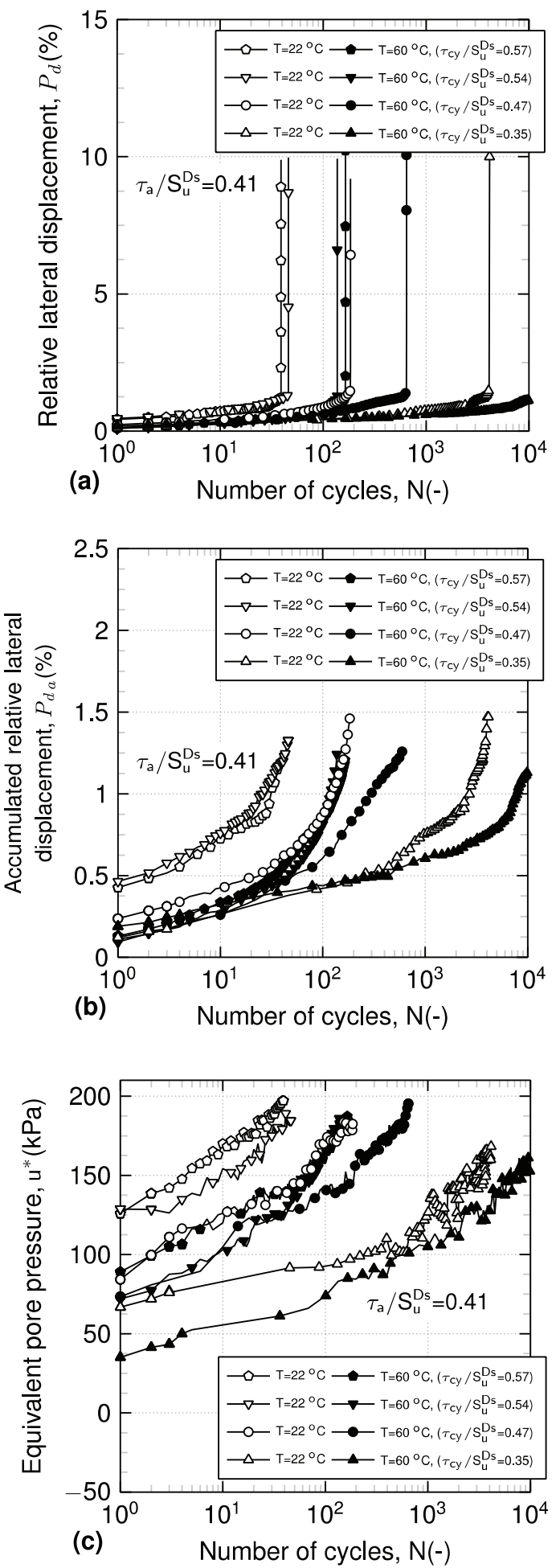

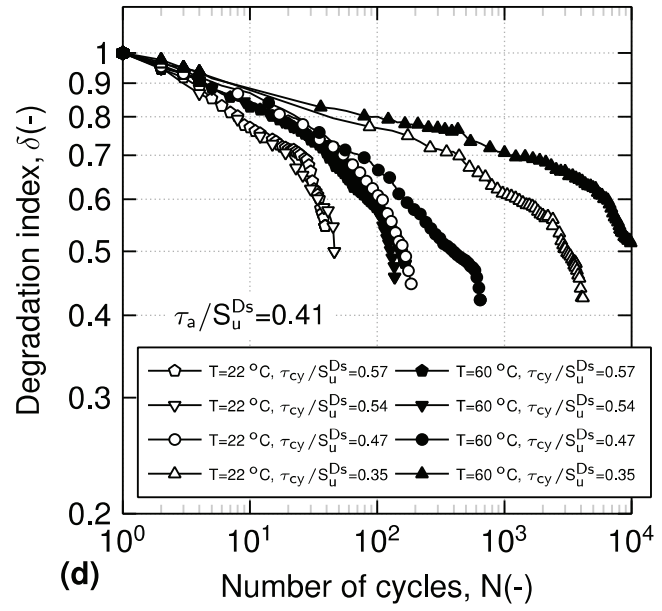

Fig. 5. Cyclic CVEU clay-structure interface test results at 22 and $60{ }^{\circ} \mathrm{C}$.

The number of cycles to failure upon cycling at elevated temperatures for all of the different CSR values increased by 2.5-4 times. The permanent relative lateral displacement evolution versus the number of cycles is depicted in Fig. 5b. The CSR reduction from 0.57 to 0.35 decreased the relative lateral displacement of the first cycle from 0.48 to $0.12 \%$. Heating reduced the permanent relative lateral displacement of the first cycle for $\tau_{c y} / S_{u}^{D S}$ $=0.57$ from 0.42 to $0.13 \%$ which is a reduction of $69 \%$. The equivalent pore pressure $\mathrm{u}^{*}$, of the first cycle was larger when CSR was higher (Fig. 5c). Heated samples have lower equivalent pore pressure $\mathrm{u}^{*}$, than unheated ones. Higher CSR values, raised the degradation index rate (Fig. 5d). For CSR value of 0.35 the degradation index of 0.6 was obtained in around 1000 cycles, while for a CSR value of 0.47 , the same degradation index could be obtained with only 100 cycles. Considering the effect of temperature, the degradation index decreased for heated samples and they showed less tendency to degrade compared to unheated samples. The degradation index of 0.6 for the test with CSR of 0.53 at $22^{\circ} \mathrm{C}$ was obtained in 35 cycles while for the heated sample, it was obtained in 100 cycles.

\section{Discussion}

The recorded results are discussed in this section to clarify (i) the effect of cyclic stress variations at different temperatures and (ii) the thermal effects on strain accumulation, equivalent pore pressure generation and degradation of clay-structure. Fig. 6 shows the cyclic loops for an ASR of 0.41 and CSRs of 0.57, 0.47 and 0.35 at different temperatures. The cyclic loops of $\mathrm{N}=10$ for a CSR of 0.57 are compared with their counterparts at different temperatures in Fig. 6b and Fig. 6c.

The cyclic hysteresis at higher temperatures for $\mathrm{N}=10$ at $60{ }^{\circ} \mathrm{C}$ are steeper compared to those of the unheated samples which may be due to the denser state of the heated samples. It is also observed that the areas encompassed by the hysteresis loop in heated samples are smaller than those in unheated samples in clay-structure interface tests, 
implying that less energy is dissipated in heated samples. [15] by performing temperature-controlled undrained cyclic triaxial tests on kaolin have reported that, the cyclic hysteresis loops at higher temperatures are more regular and straighter, with steeper loading-unloading curves compared with those of the heated samples which, is consistent with responses observed in this study. For a CSR of 0.47 , the effect of temperature on cyclic loops is less pronounced (Fig. 6c). For a CSR of 0.35, there is almost no noticeable difference among $\mathrm{N}=10$ hysteresis loops at different temperatures compared to those at other CSR values (Figs. 6a and 6b). The reduction in the CSR value ceases the effect of temperature on cyclic hysteresis loops and the difference between the heated and unheated loops becomes relatively insignificant. This may be due to the fact that, in lower CSR values the cyclic loads are in plastic shakedown but at higher CSR values, the cyclic loads reach the ratcheting response; therefore, the effect of temperature is more pronounced.

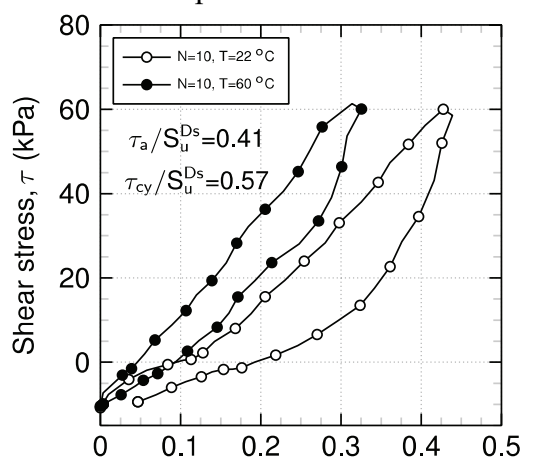

a) Relative lateral displacement, $P_{d}^{*}(\%)$

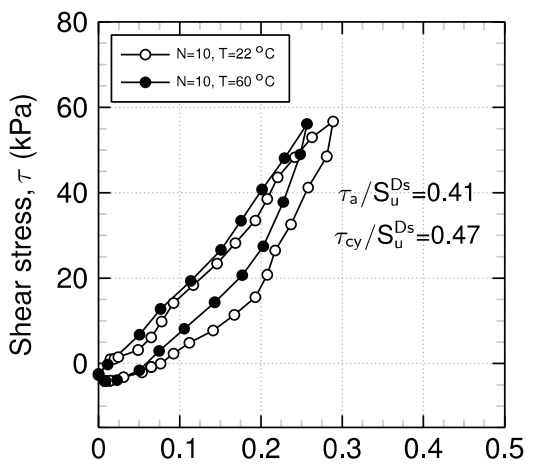

b) Relative lateral displacement, $P_{d}^{*}(\%)$

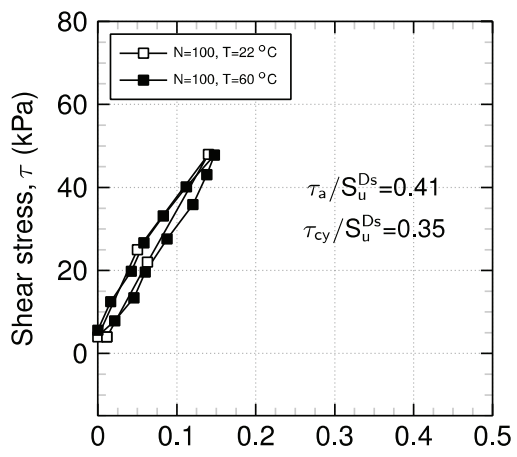

c) Relative lateral displacement, $P_{d}^{*}(\%)$

Fig. 6. Cyclic loops at different temperatures $P_{d}{ }^{*}=$ relative lateral displacement from the beginning of cycle $\mathrm{N}$.
Based on the three different CSR values compared in Fig. 7, it can be observed that at a CSR less than 0.47 $\left(\tau_{c y} / S_{u}^{D S}\right)$, the effect of temperature on cyclic characteristics of clay-structure interface is negligible. [22] by conducting cyclic CVEU simple shear tests on kaolinite have observed that beyond a threshold of cyclic shear strain of 0.012 and $0.014 \%$, the degradation rate and pore pressure generation is not evolved with further cycling.

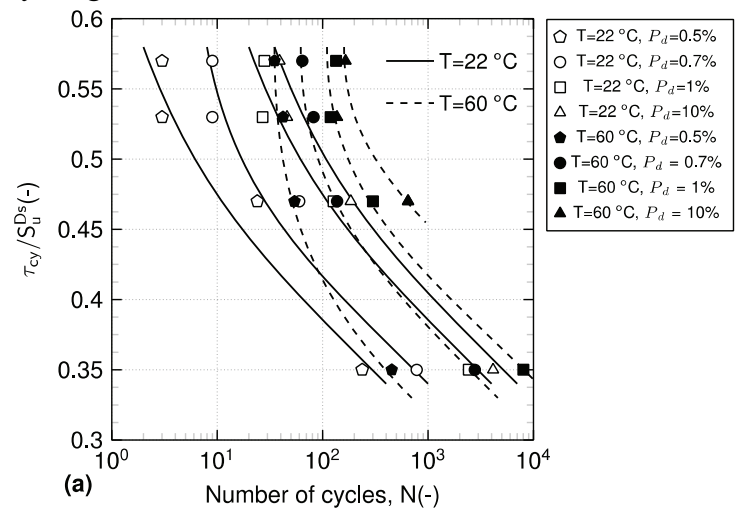

Fig. 7. $\tau_{c y} / S_{u}^{D S}$ vs number of cycles curve as a function of shear strain.

The values of the degradation parameter " $t$ " in Fig. 8 are the slopes of the lines fitted through the logarithm of number of cycles versus logarithm of degradation index data points for cyclic tests. At $22{ }^{\circ} \mathrm{C}$ with increasing CSR from 0.35 to 0.57 , the degradation parameter increases from 0.064 to 0.115 but for tests at $60{ }^{\circ} \mathrm{C}$ the degradation parameter increases from 0.049 to 0.097 for the same range of CSR. The degradation parameters for heated samples are lower than the tests at $22{ }^{\circ} \mathrm{C}$ which can be due to the denser state of the samples that reduces the rate of degradation. The degradation rate for the CSR range between 0.35 to 0.57 decreases about $16 \%$ for a temperature increase from 20 to $60{ }^{\circ} \mathrm{C}$. On the basis of CVEU simple shear tests on kaolinite (clay-clay type), [22] have reported that, in the cyclic strain range of 0.1 $0.5 \%$, with an vertical stress increase from 220 to $680 \mathrm{kPa}$, degradation parameter reduces by $20-38 \%$, which can be comparable to the decrease have been obtained by heating in this study. The thermal overconsolidation phenomena, play the same role as mechanical loading.

\section{Conclusions}

This study presents an investigation of the effect of cyclic parameter variations on clay-structure interface behavior at different temperatures $\left(22\right.$ and $\left.60^{\circ} \mathrm{C}\right)$. Constant-volume equivalent-undrained (CVEU) monotonic and cyclic clayclay and clay-structure tests were performed. The strain accumulation, equivalent excess pore pressure, degradation index and stress-strain hysteresis loops are presented and discussed. The following conclusions are obtained: 


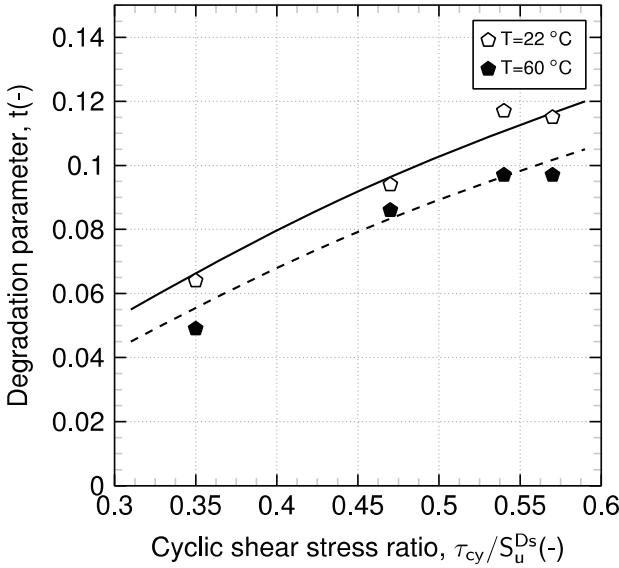

Fig. 8. Evolution of degradation parameter, $t$ with cyclic stress ration variation at different temperatures (22 and $\left.60^{\circ} \mathrm{C}\right)$.

- In monotonic CVEU tests, the shear behavior of the clay-structure is different from the clay-clay one. The peak, strain softening and effective stress reduction differences confirm that the shear occurs in the interface zone. The virgin monotonic behavior of the clay-clay and clay-structure interface, shows the limit which the cyclic loads cannot go beyond.

- The results clearly show the difference between cyclic behavior of the clay-clay and clay-structure interface tests. The number of cycles to failure for clay-structure test is lower than that for the clay-clay one due to the difference in their strain softening mode.

- In cyclic behavior of interface, decreasing the cyclic stress ratio (CSR) increases the number of cycles to failure and decreases the equivalent pore pressure and degradation index.

- The temperature increase from 22 to $60{ }^{\circ} \mathrm{C}$, substantially increases the number of cycles to failure. For almost all of the cyclic clay-structure interface tests, the shear strain and equivalent pore pressure corresponding to the first cycle decrease after heating. Drained heating of the normally consolidated kaolin, causes thermal overconsolidation and makes the sample denser, which may be one of the reasons for the increase in the number of cycles to failure. The denser state of the heated samples compared to the unheated samples reduces the rate of degradation.

- Reducing the average shear stress, decreases the number of cycles to failure. The samples are subjected to higher negative shear stresses and therefore, the resistance against cycles are reduced.

- Normally consolidated kaolin clay with the characteristics in this study subjected to cyclic stresses mentioned in this study by heating from 22 to $60{ }^{\circ} \mathrm{C}$, shows higher number of cycles to failure.

Further investigations should be carried out to investigate the effect of monotonic and cyclic temperature variations on the one-way and two-way cyclic behavior of normally consolidated an overconsolidated clay-clay and claystructure interface.

\section{References}

1. Brandl, H. (2006). Géotechnique, 56(2), 81-122.

2. Bourne-Webb, P. J., Amatya, B., Soga, K., Amis, T., Davidson, C., \& Payne, P. (2009). Géotechnique, 59(3), 237-248.

3. Murphy, K. D., McCartney, J. S., \& Henry, K. S. (2015). Acta Geotechnica, 10(2), 179-195.

4. Faizal, M., Bouazza, A., Haberfield, C., \& McCartney, J. S. (2018). Journal of Geotechnical and Geoenvironmental Engineering, 144(10), 04018072 .

5. Lahoori, M., Jannot, Y., Rosin-Paumier, S., Boukelia, A., \& Masrouri, F. (2020). Applied Thermal Engineering, 167, 114795.

6. Fakharian, K., \& Evgin, E. (1997). Journal of Geotechnical and Geoenvironmental Engineering, 123(12), 1096-1105.

7. Pra-ai, S., \& Boulon, M. (2017). Acta Geotechnica, 12(1), 107-127.

8. Lemos, L. J. L., \& Vaughan, P. R. (2009). In Selected Papers on Geotechnical Engineering by $P R$ Vaughan (pp. 392-401). Thomas Telford Publishing.

9. Di Donna, A., Ferrari, A., \& Laloui, L. (2016). Canadian Geotechnical Journal, 53(4), 659672.

10. Martinez, A., \& Stutz, H. H. (2019). Géotechnique, 69(9), 801-815.

11. Zhou, J., \& Gong, X. (2001). Canadian Geotechnical Journal, 38(1), 208-212.

12. Andersen, K. H. (2009). Canadian Geotechnical Journal, 46(5), 513-535.

13. Wichtmann, T., Andersen, K. H., Sjursen, M. A., \& Berre, T. (2013). Canadian Geotechnical Journal, 50(4), 400-412.

14. Idriss, I. M., Dobry, R. M., Doyle, E. H., \& Singh, R. D. (1976, January). In Offshore Technology Conference.

15. Cekerevac, C., \& Laloui, L. (2010). Géotechnique, 60(8), 651-655.

16. Maghsoodi, S., Cuisinier, O., \& Masrouri, F. (2020). Canadian Geotechnical Journal, 57(1), 3247.

17. Yazdani, S., Helwany, S., \& Olgun, G. (2019). Geomechanics for Energy and the Environment, 18, 69-78.

18. Murphy, K. D., \& McCartney, J. S. (2014). Thermal borehole shear device. Geotechnical Testing Journal, 37(6), 1040-1055.

19. Maghsoodi, S., Cuisinier, O., \& Masrouri, F. (2019). In E3S Web of Conferences (Vol. 92, p. 10002).

20. Maghsoodi, S., Cuisinier, O., \& Masrouri, F. In 17th European Conference on Soil Mechanics and Geotechnical Engineering (2019c).

21. Dyvik, R., Berre, T., Lacasse, S., \& Raadim, B. (1987). Geotechnique, 37(1), 3-10. 
22. Mortezaie, A. R., \& Vucetic, M. (2013). Journal of Geotechnical and Geoenvironmental Engineering, 139(10), 1727-1737.

23. Hanzawa, H., Nutt, N., Lunne, T., Tang, Y. X., \& Long, M. (2007). Soils and Foundations, 47(1), 4758.

24. Maghsoodi, S., Cuisinier, O., \& Masrouri, F. (2020). Journal of Geotechnical and Geoenvironmental Engineering. doi.org/10.1061/(ASCE)GT.1943-5606.0002360. 